\title{
Direct-Fed Microbials Alter Ruminal in vitro Gas Production and Fermentation with a High-Concentrate Diet
}

\author{
Kenney NM, Vanzant ES, Harmon DL, and McLeod KR* \\ Department of Animal and Food Science, University of Kentucky, USA
}

*Corresponding author: McLeod KR, Department of Animal and Food Sciences, University of Kentucky, Lexington, Kentucky, USA, E-mail: kyle.mcleod@uky.edu

Received: 22 Jan, 2020 | Accepted: 24 Feb, 2020 | Published: 28 Feb, 2020

Citation: Kenney NM, Vanzant ES, Harmon DL, McLeod KR (2020) Direct-Fed Microbials Alter Ruminal in vitro Gas Production and Fermentation with a High-Concentrate Diet. J Anim Sci Res 4(1): dx.doi.org/10.16966/2576-6457.134

Copyright: (C) 2020 Kenney NM, et al. This is an open-access article distributed under the terms of the Creative Commons Attribution License, which permits unrestricted use, distribution, and reproduction in any medium, provided the original author and source are credited.

\begin{abstract}
Ruminal fermentation can be altered with Direct-Fed Microbials (DFM) although these responses may depend on the length of time that DFM has been supplied. To test this hypothesis, 12 ruminally cannulated Angus steers (385 $\pm 35 \mathrm{~kg}$ ) were used in a split-split plot design with dietary treatment, control or DFM, in the whole plot, treatment of the incubation media, control or DFM in the sub plot, and length of dietary treatment (14 and $28 \mathrm{~d}$ ) in the sub-sub plot. The DFM was a mixed culture of lactate producing bacteria, primarily Lactobacillus acidophilus and Enterococcus faecium, fed at $10^{9} \mathrm{cfu} /$ day. A 90:10 concentrate to forage, corn-based diet was fed twice daily and top-dressed with DFM or its lactose carrier. Media DFM dosage $(50,000 \mathrm{cfu})$ provided the same cfu per unit of dry matter as provided in the diet. Gas production decreased $(P=0.02)$ with dietary DFM and tended $(P=0.06)$ to decrease with media DFM. A diet by media interaction $(P<0.01)$ was observed for gas production rate; rate was decreased by media DFM without dietary DFM but increased with media DFM with dietary DFM. Volatile Fatty Acid (VFA) concentration tended ( $P=0.07)$ to decrease with dietary DFM; however, molar proportion of acetate was increased $(P=0.01)$. Media DFM did not alter $(P \geq 0.21)$ fermentation end products. Interactions between day and dietary DFM were not observed $(P \geq 0.14)$. Differences in gas production and fermentation end products with dietary DFM suggest that DFM altered fermentation by shifting microbial populations, while interactions between diet and media suggest that DFM also have an immediate influence on the rumen environment.
\end{abstract}

Keywords: Direct-fed microbials; In-vitro gas production; Volatile fatty acid; Cattle

\section{Introduction}

Direct Fed Microbials (DFM) consisting of cultures of Lactate Producing Bacteria (LAB) or a mixture of $\mathrm{LAB}$ and non-LAB bacteria can improve gain and growth efficiency during the receiving and finishing phases; however, these effects are often transient, occurring only during the early phases of feeding [1-4]. Currently, the mechanism(s) mediating these changes have not been identified definitively although proposed modes of action include direct antimicrobial effects via bacteriocins, competitive exclusion, and stimulation of lactate utilizing bacteria [5]. Nevertheless, the addition of DFM to the diet has shown to alter ruminal fermentation characteristics (i.e., volatile fatty acid profiles, $\mathrm{pH}$ ) [6-9]. To date, the response of the rumen environment to DFM provision over time has not been characterized. Effects of DFM on the rumen environment may differ across the time course of the feeding period and differences may also exist between inclusions of DFM in the diet versus a single dose administration to the fermentation vessel. This has implications beyond simple methodological considerations. Understanding the adaptive, as compared with immediate effects of DFM on the ruminal microbiota would be informative to identifying mechanisms of DFM action in the rumen.
By simulating the rumen environment, the in vitro gas production technique allows characterization of DFM mediated changes in the rumen. Previous in vitro gas production experiments have focused primarily on the effects of providing Saccharomyces cerevisiae or combinations of yeast and various Lactobacilli strains and have produced variable results on the impact on gas production and the formation of endpoint fermentation end products [10-12]; however, there is limited data on the impact of bacterial DFM on in vitro gas production [2]. This study was designed to differentiate between immediate (in vitro, addition to fermentation vessel) and adaptive (in vivo, consumed for $28 \mathrm{~d}$ ) effects of LAB containing DFM on ruminal in vitro fermentation of high concentrate substrates, as indicated by alterations in gas production and fermentation end products.

\section{Materials and Methods}

\section{Experimental design and treatments}

All procedures were approved by the University of Kentucky Institutional Animal Care and Use Committee. Twelve ruminally cannulated Angus steers (initial body weight $385 \pm 35 \mathrm{~kg}$ ) were used in a split-split plot design experiment (Figure 1). The whole plot consisted of steer and dietary DFM provision; the subplot consisted of the in vitro fermentation vessel and media DFM, and within sub-plot 


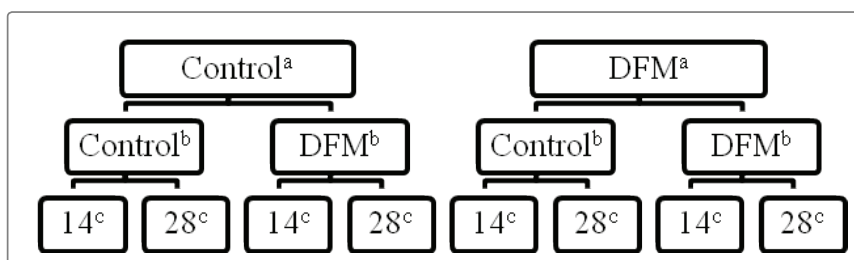

Figure 1: Experimental design.

aWole plot; Steer supplemented with either ground corn carrier (control) or dietary, or DFM, Direct-fed microbial; $\left(10^{9} \mathrm{cfu} /\right.$ day; $10 \mathrm{~g}$, Vit-E-Men Co., Norfolk, NE, USA).

bSub-plot; Fermentation vessel with addition of lactose carrier (control) or DFM, Direct-fed microbial; $(50,000 \mathrm{cfu} ; 10 \mathrm{~g}$, Vit-E-Men Co., Norfolk, NE, USA).

'Day of sampling relative to initiation of whole plot treatment.

(sub-sub plot), time of in vitro run (14 and $28 \mathrm{~d}$ ), relative to initiation of dietary DFM provision.

Initiation of dietary DFM treatment was staggered to ensure that only three steers served as rumen fluid donors for in vitro gas production at each sampling day ( 14 and $28 \mathrm{~d}$ ), resulting in 4 blocks of 3 steers each. The limitation on number of steers serving as fluid donors each day resulted in unequal representation of treatments in each block. Treatments were randomly assigned to animals and animals randomly assigned to blocks with the constraint that each treatment is represented in each block. In vitro gas production was determined on days 14 and 28 subsequent to initiation of dietary treatments. These sampling days were chosen based on previous research in which positive effects of DFM on performance were largely limited to the first $28 \mathrm{~d}$ of feeding (Kenney et al., 2015a, b) [13,14].

Steers were housed indoors in individual pens $(3.0 \times 3.7 \mathrm{~m})$ with free access to water and a $16 \mathrm{hr}$ light and $8 \mathrm{hr}$ dark cycle. Animals were fed a high concentrate, Total Mixed Ration (TMR) twice daily at $2.0 \times$ NEm (NRC, 2000; Table 1). The TMR was prepared weekly and stored in a walk in freezer $\left(-20^{\circ} \mathrm{C}\right)$. Ingredient dry matter concentrations were determined weekly, prior to mixing the next load of TMR, by drying for 24 hours in a forced air oven $\left(100^{\circ} \mathrm{C}\right.$, Model 1690 , VWR scientific Products, Cornelius, OR). Diet adaptation occurred over 26 days through the use of two transitional diets. Animals were adapted to the final diet for 10 days before the initiation of treatments. Following adaptation to the final diet, beginning day one of the experimental period, diets were top-dressed twice daily with DFM $\left(10^{9} \mathrm{cfu} /\right.$ day $)$ in a corn carrier or a control consisting of the corn carrier. The DFM consisted of a mixed bacterial culture which consisted primarily of Lactobacillus acidophilus and Enterococcus faecium but also included Pediococcus acidilacticii, Lactobacillus brevis, and Lactobacillus plantarum (10 g, Vit-E-Men Co., Norfolk, NE, USA).

\section{In vitro gas production}

Each steer provided rumen fluid for six fermentation modules, resulting in 3 replicates per sub-plot treatment. Rumen contents were collected from the ventral rumen of each steer prior to morning feeding. Separate media solutions were prepared for each steer using the following procedure. Ruminal contents were processed using an immersion blender for 2 minutes and strained through 4 layers of cheesecloth. Buffer solution, macro- and micro-mineral solutions, and reducing solution were prepared as described previously [15]. These solutions $(1100 \mathrm{ml})$ were combined with $200 \mathrm{ml}$ of rumen fluid, the product being the media solution added to the fermentation vessels,
Table 1: Ingredient composition of total mixed ration.

\begin{tabular}{|c|c|c|c|}
\hline & \multicolumn{3}{|c|}{ Total Mixed Ration } \\
\hline & Step-up Diet 1 & Step-up Diet 2 & Final Diet \\
\hline \multicolumn{4}{|c|}{ Ingredient Composition ( $\mathrm{g} \mathrm{kg}^{-1} \mathrm{DM}$ ) } \\
\hline Dry Distillers Grain & 200 & 200 & 200 \\
\hline Corn Silage & 200 & 125 & 50 \\
\hline Alfalfa Silage & 200 & 125 & 50 \\
\hline Steam Flaked Corn & 210 & 315 & 420 \\
\hline High Moisture Corn & 90 & 135 & 180 \\
\hline Ground Corn & 68.8 & 68.8 & 68.8 \\
\hline Limestone & 20 & 20 & 20 \\
\hline Trace Mineral Premix ${ }^{2}$ & 5.0 & 5.0 & 5.0 \\
\hline Urea & 3.5 & 3.5 & 3.5 \\
\hline Tallow & 2.5 & 2.5 & 2.5 \\
\hline Vitamin Premix ${ }^{y}$ & 0.2 & 0.2 & 0.2 \\
\hline Thiamine $91 \%$ & 0.005 & 0.005 & 0.005 \\
\hline \multicolumn{4}{|c|}{ Chemical Composition $^{x}$ (g kg $\left.^{-1} \mathrm{DM}\right)$} \\
\hline Dry Matter & 520 & 585 & 670 \\
\hline Crude Protein & 161 & 156 & 151 \\
\hline Ether Extract & 56 & 58 & 60 \\
\hline Neutral Detergent Fiber & 276 & 221 & 165 \\
\hline NEm, M cal/kg & 1.83 & 1.98 & 2.11 \\
\hline
\end{tabular}

${ }^{2}$ Trace Mineral Premix-Salt, not less than 92\% not greater than 96\%, Zinc $0.55 \%$, Iron $0.93 \%$, Manganese $0.48 \%$, Copper $0.18 \%$, lodine $0.01 \%$, Selenium 0.01\%, Cobalt 0.01\% (2653L, Burkmann Feeds, Danville, KY).

'Vitamin Premix-Vitamin A 1,818,182 IU/kg, Vitamin D 363,000 IU/kg, Vitamin E $227 \mathrm{IU} / \mathrm{kg}$.

${ }^{x}$ Chemical composition represents formulated values; minerals and vitamins $A, D$, and $E$ were fed.

To meet requirements for beef steers growing at $1.1 \mathrm{~kg} / \mathrm{d}$ (NRC, 2000)

and maintained under a $\mathrm{CO}_{2}$ atmosphere until added to the $250 \mathrm{ml}$ fermentation vessels. Fermentation vessels were provided with 400 mg substrate (296 mg, dry matter basis); the substrate consisted of the TMR freeze ground with a Wiley Mill to pass through a 1-mm screen. Additionally, each fermentation vessel received $2 \mathrm{ml}$ of $\mathrm{H}_{2} \mathrm{O}$, $100 \mathrm{ml}$ of media solution, and $1 \mathrm{ml}$ of the media treatment. The media treatment consisted of DFM plus lactose carrier $(50,000 \mathrm{cfu})$ or lactose control. The media DFM dosage provided the same cfu per unit of substrate dry matter as provided to the animal by the diet. Vessels were gassed with $\mathrm{CO}_{2}$ for 30 seconds and then fitted with remote automatic pressure transducers (Ankom RF Wireless Gas Production System, Ankom Technology, Macedon, NY). Vessels were incubated in a water bath at $39^{\circ} \mathrm{C}$ for 30 hours and accumulated gas pressure was measured at 5 minute intervals. Preliminary work indicated that 30 hours of fermentation was required to reach plateau in order to allow accurate modeling of gas production kinetics. At the end of the fermentation, the accumulated gas was released, $\mathrm{pH}$ was determined immediately using a portable $\mathrm{pH}$ meter (Acorn $\mathrm{pH} 6$ Meter, Oakton Instruments, Vernon Hills, IL, USA), and samples of the culture broth were collected. A $5 \mathrm{ml}$ portion of the sample was combined with 0.5 
$\mathrm{ml}$ of metaphosphoric acid $(25 \mathrm{~g} / 100 \mathrm{ml})$ and $0.5 \mathrm{ml}$ of Volatile Fatty Acid (VFA) internal standard (1 g/100 $\mathrm{ml}$ 2-ethylbutyrate) and frozen for later analysis. A second $5 \mathrm{ml}$ sample was frozen for analysis of ammonia and DL-lactate.

\section{Sample analysis}

Culture broth VFA concentrations were determined by a gas chromatograph (6890 Hewlett-Packard, Avondale, PA, USA), fitted with a Supelco 25326 Nukol fused silica capillary column $(15 \mathrm{~m} \times 0.53$ $\mathrm{mm} \times 0.05$ um film thickness; Sigma/Supelco, Bellefonte, PA, USA) following procedures described previously $[16,17]$. Konelab analysis (Model 20XTi, Thermo Fisher Scientific, Waltham, MA, USA) was used to determine $\mathrm{NH}_{3}-\mathrm{N}$ concentrations following procedures described previously [18]. DL-lactate was determined by gas chromatography (Model 6890N, Network GC, Agilent Technologies, Santa Clara, CA, USA) following the derivatization of culture broth samples $[19,20]$ using ${ }^{13} \mathrm{C}$-lactate as the internal standard.

\section{Calculations}

Head space volume for each incubation flask $(206 \pm 4.7 \mathrm{~mL})$ was determined by subtracting additions of media, substrate, and treatments from total volume (water displacement). Cumulative gas pressure readings were converted to gas volumes using the ideal gas law. Gas volume parameters for individual modules were quantified using the best fit-model from the evaluation of ten gas production models [21]. The best fit model was determined to be the Fitzhugh model $\left(1 \pm \mathrm{e}^{-\mathrm{rt}}\right)^{\mathrm{n}}$, which describes gas volume as a function of time. The variable $\mathrm{t}$ represents time, and $\mathrm{r}$ and $\mathrm{n}$ are rate parameters determined by least-squares fit. When $\mathrm{n}>0$ the lower sign was used and when $\mathrm{n}<0$ the upper sign was used.

\section{Statistical analysis}

In vitro gas production model outputs (total $\mathrm{ml}$ of gas and rate of gas production) and fermentation end product measures were analyzed as a split-split plot design using the GLM procedure (SAS Inst. Inc., Cary, NC). Prior to statistical analysis, values for each of the three replicate vessels were compiled into mean values for all response variables. Dietary treatment was considered the whole-plot and media treatment was considered the sub-plot, and day relative to initiation of dietary treatment was the sub-sub-plot. Experimental units were: animal for the whole plot ( $\mathrm{n}=6 / \mathrm{trt}$ within day), incubation vessel for the sub-plot ( $\mathrm{n}=12 /$ trt within day) and day within incubation vessel for the sub-sub-plot $(n=24)$. The model statement included terms for dietary treatment, media treatment, block, day, and their interactions. The interaction between dietary treatment and block and the threeway interaction between dietary treatment, media treatment and block were considered random effects and used to test the whole plot effect (dietary treatment), and sub-plot effect (media treatment), respectively. The residual error was used to test the sub-sub-plot factor (day relative to initiation of dietary treatment). When interactions were significant, means were separated using least significant differences. Statistical significance was characterized at $\mathrm{P}<0.05$ and a tendency for significance at $0.05<\mathrm{P}<0.10$.

\section{Results}

Three way interactions between dietary treatment, media treatment, and time (day) were not detected $(\mathrm{P} \geq 0.35)$ for gas production measures or fermentation end products. Similarly, no interactions existed between day and dietary or media DFM treatment $(\mathrm{P}>0.14)$ for gas production measures. Dietary treatment with DFM decreased $(\mathrm{P}=0.02)$ total gas production (Table 2$)$. Similarly, there was a tendency $(\mathrm{P}=0.06)$ for DFM treatment of the media to decrease total gas production. Total gas production tended $(\mathrm{P}=0.06)$ to increase from day 14 to 28. A diet DFM by media DFM interaction occurred $(\mathrm{P} \leq 0.01)$ for rate of gas production. In the absence of dietary DFM treatment, media DFM treatment decreased rate of gas production. Conversely, with inclusion of DFM in the diet, DFM treatment of the media increased the gas production rate (Figure 2). Rate of gas production increased $(\mathrm{P}=0.02)$ from day 14 to 28 .

Interactions were not observed $(\mathrm{P} \geq 0.18)$ between dietary treatment and media treatment for fermentation end products. Supplying DFM in the diet tended $(\mathrm{P}=0.07)$ to decrease the total VFA concentration of the culture broth (Table 2). Acetate and propionate concentrations did not differ $(P \geq 0.18)$ with dietary DFM treatment; however, provision of DFM in the diet decreased $(\mathrm{P}=0.04)$ butyrate concentration. The molar proportion of acetate was increased $(\mathrm{P}=0.01)$ with dietary DFM treatment; however, the molar proportions of propionate and butyrate did not differ $(P \geq 0.19)$ with dietary DFM treatment. Diet treatment did not impact $(\mathrm{P} \geq 0.12)$ the acetate to propionate ratio, DL-lactate concentration, ammonia- $\mathrm{N}$ concentration, or culture broth $\mathrm{pH}$.

Total VFA concentrations $(\mathrm{P}=0.40)$ did not differ with $\mathrm{DFM}$ addition to the media. Supplying DFM to the media did not impact $(P \geq 0.26)$ acetate, propionate, or butyrate concentrations. Similarly, molar proportions of acetate, propionate, and butyrate and the acetate to propionate ratio were not altered $(\mathrm{P} \geq 0.59)$ by media DFM application. No impacts $(\mathrm{P} \geq 0.31)$ of media treatment on DL-lactate concentrations, ammonia- $\mathrm{N}$ concentration or culture broth $\mathrm{pH}$ were observed.

Total VFA concentration decreased $(\mathrm{P}=0.0002)$ from day 14 to $\mathrm{d} 28$. Acetate and butyrate concentrations decreased $(\mathrm{P} \leq 0.0001)$ from day 14 to 28 . Propionate concentration was not impacted $(\mathrm{P}=0.43)$ by time. Consequently, molar proportion of acetate was decreased $(\mathrm{P}=0.0002)$ and the propionate molar proportion increased $(\mathrm{P}=0.04)$ from day 14 to 28. Additionally, the molar proportion of butyrate tended $(\mathrm{P}=0.06)$ to decrease over time. The acetate to propionate ratio decreased from day 14 to $28(\mathrm{P}=0.0007)$. DL-lactate concentrations increased

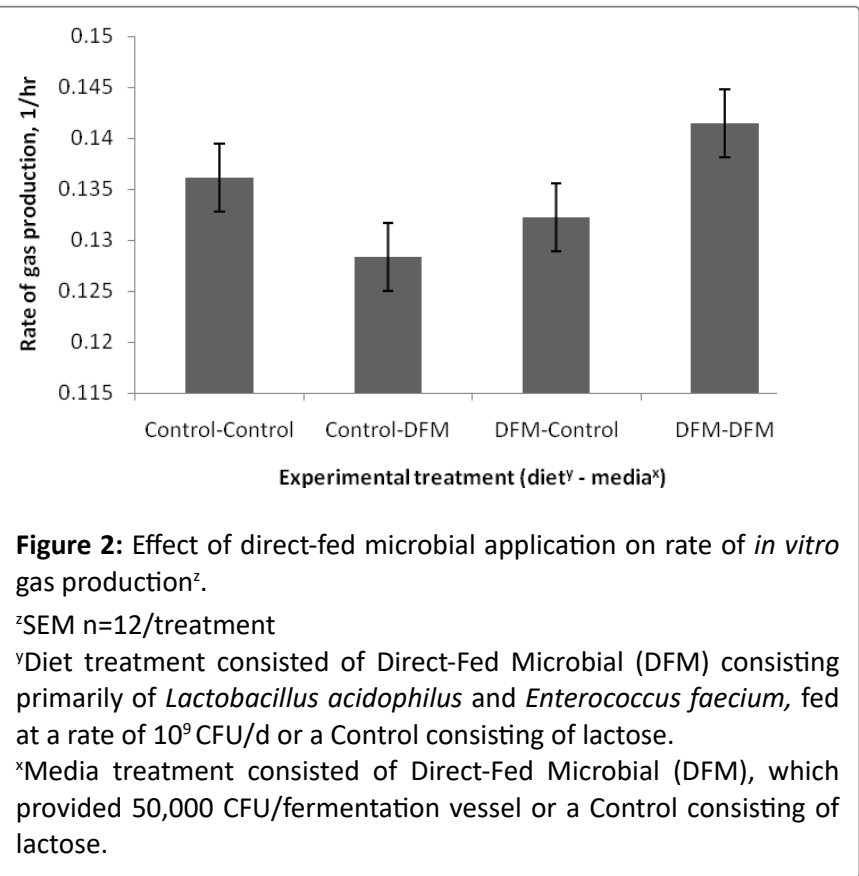


Table 2: Effect of diet and media direct-fed microbial application and day on gas production measures and in vitro fermentation end products.

\begin{tabular}{|c|c|c|c|c|c|c|c|c|c|c|c|c|}
\hline & \multicolumn{2}{|c|}{ Diet } & \multirow[b]{2}{*}{ SEM $^{y x}$} & \multicolumn{2}{|c|}{ Media } & \multirow[b]{2}{*}{ SEM ${ }^{w}$} & \multicolumn{2}{|c|}{ Day } & \multirow[b]{2}{*}{ SEM $^{v}$} & \multicolumn{3}{|c|}{ P Value } \\
\hline & Control & DFM $^{2}$ & & Control & DFM & & 14 & 28 & & Diet & Media & Day \\
\hline \multicolumn{13}{|l|}{ Gas production } \\
\hline Total, $\mathrm{ml}^{\mathrm{u}}$ & 148.6 & 131.1 & 5.45 & 143.2 & 136.5 & 5.45 & 132.6 & 147.1 & 5.29 & 0.02 & 0.07 & 0.06 \\
\hline Rate, $1 / \mathrm{hr}^{\mathrm{t}}$ & - & - & - & - & - & - & 0.127 & 0.142 & 0.005 & 0.79 & 0.49 & 0.02 \\
\hline Total VFA, mM & 80.86 & 72.26 & 2.16 & 77.37 & 75.76 & 1.16 & 81.79 & 71.33 & 1.76 & 0.07 & 0.40 & $<0.01$ \\
\hline Acetate & 41.92 & 39.42 & 1.03 & 40.96 & 40.39 & 0.65 & 44.75 & 36.60 & 0.96 & 0.18 & 0.58 & $<0.01$ \\
\hline Propionate & 16.51 & 14.20 & 0.99 & 15.49 & 15.21 & 0.13 & 14.88 & 15.82 & 0.85 & 0.20 & 0.24 & 0.43 \\
\hline Butyrate & 12.32 & 10.02 & 0.50 & 11.53 & 11.11 & 0.22 & 12.66 & 9.98 & 0.43 & 0.04 & 0.26 & $<0.01$ \\
\hline \multicolumn{13}{|c|}{ Molar Proportion, $\mathrm{mol} / 100 \mathrm{~mol}$} \\
\hline Acetate & 52.00 & 54.38 & 0.29 & 52.95 & 53.41 & 0.20 & 54.90 & 51.47 & 0.57 & 0.01 & 0.21 & $<0.01$ \\
\hline Propionate & 20.27 & 19.89 & 0.80 & 20.11 & 20.01 & 0.14 & 18.16 & 22.00 & 0.89 & 0.76 & 0.75 & $<0.01$ \\
\hline Butyrate & 15.63 & 13.71 & 0.81 & 14.75 & 14.59 & 0.08 & 15.40 & 13.94 & 0.54 & 0.19 & 0.26 & 0.06 \\
\hline $\begin{array}{l}\text { Acetate: } \\
\text { Propionate }\end{array}$ & 2.68 & 2.91 & 0.10 & 2.78 & 2.81 & 0.04 & 3.09 & 2.50 & 0.11 & 0.19 & 0.63 & $<0.01$ \\
\hline DL-Lactate $\mathrm{mM}$ & 0.071 & 0.070 & 0.002 & 0.070 & 0.070 & 0.003 & 0.036 & 0.104 & 0.002 & 0.48 & 0.96 & $<0.01$ \\
\hline $\mathrm{NH}_{3}-\mathrm{N} \mathrm{mM}$ & 18.22 & 15.50 & 0.99 & 16.65 & 17.07 & 0.36 & 17.60 & 16.12 & 1.35 & 0.15 & 0.47 & 0.43 \\
\hline $\mathrm{pH}$ & 6.38 & 6.46 & 0.03 & 6.42 & 6.42 & 0.003 & 6.30 & 6.54 & 0.02 & 0.13 & 0.31 & $<0.01$ \\
\hline
\end{tabular}

¿DFM: Direct-Fed Microbial consisting primarily of Lactobacillus acidophilus and Enterococcus faecium, fed at $10^{9}$ cfu/day.

ySEM: Standard Error of the Mean.

${ }^{x} n=12 /$ treatment.

${ }^{w} n=24 /$ treatment.

${ }^{v} n=24 /$ day.

uTotal: No interactions $P \geq 0.39$.

tRate: Diet $\times$ Media $\mathrm{P}=0.009$ (refer to Figure 2).

$(\mathrm{P}<0.0001)$ over time. Ammonia- $\mathrm{N}$ was not impacted $(\mathrm{P}=0.43)$ by time, but culture broth $\mathrm{pH}$ increased $(\mathrm{P}<0.01)$ from day 14 to 28 .

\section{Discussion}

Dietary DFM treatment with a mixed bacterial culture of lactateproducing DFM, primarily consisting of Lactobacillus acidophilus and Enterococcus faecium, resulted in a decrease in total gas production; this is indicative of a decrease in the extent of substrate degradation and therefore suggests that extent of ruminal fermentation was decreased by feeding this DFM [22]. This was accompanied by a tendency for a decrease in total VFA concentrations, which gives further support for diminished ruminal fermentation with dietary DFM treatment. However, it is possible that differences in the inoculum at the initiation of incubation influenced the observed concentrations of end products after $30 \mathrm{~h}$ of incubation. In a separate publication, we reported on in vivo effects of DFM in a study ran concurrently and used the same rumen fluid inoculum as that of the study reported in this manuscript [14]. In that report, we found no significant differences in concentrations of acetate, propionate, butyrate, or total VFA on d 14 or d 28. However, numerical differences in total VFA concentrations at the end of the incubation in the present study $(11.9 \%$ greater for control) were proportionally similar to differences in initial inoculum concentrations ( $12.6 \%$ greater for control).

Application of DFM directly to the media also resulted in a tendency for decreased total gas production, although there were no changes in fermentation end products. Similarly, Baah J, et al. [2] observed a linear decrease in total gas production, as compared to control, with provision of increasing amounts of Lactobacillus case $i$ and Lactobacillus lactis after $12 \mathrm{~h}$ of in vitro fermentation; however, no differences in total gas production were observed for 6,24 , and $48 \mathrm{~h}$ fermentations. In contrast, Jeyanathan and coworkers [23] observed increased in vitro total gas production for a number of bacterial DFM strains. In both instances, DFM treatment was applied at the fermentation vessel level, with rumen fluid provided by donor cows fed a common diet with no DFM treatment.

In addition to a tendency for a decrease in total VFA concentrations, dietary DFM treatment also resulted in a decrease in butyrate concentration and an increase in the molar proportion of acetate. As discussed with total VFA, proportional changes in the postincubation concentration of butyrate and molar proportion of acetate were largely explained by differences in the initial conditions of the inoculum as reported separately [14]. Nevertheless, increases in the molar proportion of acetate suggest that methane production was increased with DFM; however, a direct measurement of methane was not obtained. Similarly, in vitro increases in the molar proportion of acetate have been observed with the provision of mixed bacterial cultures of Lactobacillus [2]. A direct measure of in vitro methane production of numerous bacterial strains indicated that methane production varied with strain (Jeyanathan et al., 2016) [23]. Increases in proportions of acetate are consistent with previous work that has demonstrated that provision of Propionibacterium in vivo decreased amylolytic bacterial numbers while increasing protozoa numbers [6]. This shift in microbial population was not accompanied by changes in the molar proportion of acetate; however, increases in the molar proportion of acetate have been observed in vivo with the provision of Propionibacterium combined with Enterococcus faecium [6]. This aligns with work by Baah J and coworkers [2], where a linear increase in acetate to propionate ratio was observed with increasing DFM provision after 12, 24, and $48 \mathrm{~h}$ of fermentation. Ammonia-N did not differ with DFM, in agreement with previous work that has found no difference in microbial $\mathrm{N}$ with DFM provision in vitro [2]. 
With dietary DFM application, changes in fermentation end products were detected, whereas addition of DFM to the in vitro media did not impact fermentation end products. This suggests that DFM may alter ruminal fermentation by inducing shifts in the microbial ecology of the rumen. This hypothesis is supported by documented shifts in microbial populations with the provision of bacterial DFM [6]. However, DFM application to the media tended to decrease total gas production, which serves as a proxy for extent of substrate degradation, and interaction for the rate of gas production between inoculum treatment and media treatment was observed. The impact of DFM application to the media on the rate of gas production depended on dietary treatment. In the absence of DFM in the diet, DFM treatment of the media resulted in a decrease in the rate of gas production. Conversely, when DFM was fed, DFM treatment of the media resulted in an increase in rate. This suggests that the microbes in the DFM interacted with the microbial populations, or otherwise altered the rumen environment, in the DFM treated donor fluid in a manner which increased the rate of digestibility while tending to decrease the extent of degradation. In the absence of dietary DFM treatment, DFM treated media resulted in a depression in the rate of digestibility and also tended to decrease the extent of degradation. The mechanisms through which these interactions are mediated are unknown. Ultimately, these results suggest that in vitro gas production experiments that entail the use of donor rumen fluid from an untreated animal and supply of treatments directly to the media may not be appropriate for studying DFM.

Total gas production tended to increase over time, regardless of DFM provision, and an increase in the rate of gas production also was observed. Total VFA concentration decreased from day 14 to 28 d. Typically, an increase in VFA concentration would be expected to accompany an increase in gas production. Although difficult to explain, it is possible that this decrease may be due to increased microbial sequestration of VFA carbon in the microbial biomass [24]. Increased gas production may be a function of increased microbial growth, therefore increasing the energy requirements of the microbial population and resulting in greater utilization of carbon. Acetate and butyrate concentrations decreased while the propionate concentration remained unchanged from day 14 to 28 . As a result, the molar proportion of propionate increased at the expense of acetate and butyrate, and therefore a decrease in the acetate to propionate ratio was observed. An increase in DL-lactate concentration was observed at day 28, which is likely, attributable to lactate's role as an intermediate in propionate production via the acrylate pathway [25]. Culture broth $\mathrm{pH}$ was increased from day 14 to 28 , presumably due to decreases in total VFA concentration. Although DL-lactate was increased at day 28 , which would typically be accompanied by a decrease in $\mathrm{pH}$, this increase was small in comparison to the decreases in total VFA observed.

\section{Conclusions}

Direct fed microbials alter in vitro gas production and fermentation end products, confirming previous work that has shown shifts in ruminal fermentation with DFM $[6,7,9,26]$. Total gas production and fermentation end products were altered with DFM provision to the donor animal, suggesting that DFM alter ruminal fermentation through shifts in microbial populations, or otherwise alter the rumen environment; however, interactions between inoculum and media treatment suggest that DFM also have more immediate influences on the rumen environment. More research will be necessary to characterize the nature of these relationships.

\section{References}

1. Elam NA, Gleghorn JF, Rivera JD, Galyean ML, Defoor PJ, et al. (2003) Effects of live cultures of Lactobacillus acidophilus (strains NP45 and NP51) and Propionibacterium freudenreichii on performance, carcass, and intestinal characteristics, and Escherichia coli strain 0157 shedding of finishing beef steers. J Anim Sci 81: 2686-2698.

2. Baah J, Wang Y, McAllister TA (2009) Impact of a mixed culture of Lactobacillus casei and L. lactis on in vitro ruminal fermentation and the growth of feedlot steers fed barley-based diets. Can J Anim Sci 89: 263-271.

3. Hutchenson DP, Cole NA, Keaton W, Graham G, Dunlap R, et al. (1980) The use of a living, nonfreeze-dried Lactobacillus acidophilus culture for receiving feedlot calves. Proc West Sec Amer Soc Anim Sci 31: 213-215.

4. Swinney-Floyd D, Gardner BA, Owens FN, Rehberger T, Parrott $T$ (1999) Effect of inoculation with either strain P-63 alone or in combination with Lactobacillus acidophilus LA53545 on performance of feedlot cattle. J Anim Sci 77.

5. McAllister TA, Beauchemin KA, Alazzeh AY, Baah J, Teather RM, et al. (2011) The use of direct fed microbials to mitigate pathogens and enhance production in cattle. Can J Anim Sci 91: 193-211.

6. Ghorbani GR, Morgavi DP, Beauchemin KA, Leedle JA (2002) Effects of bacterial direct-fed microbials on ruminal fermentation, blood variables, and the microbial populations of feedlot cattle. J Anim Sci 80: 1977-1985.

7. Beauchemin KA, Yang WZ, Morgavi DP, Ghorbani GR, Kautz W, et al. (2003) Effects of bacterial direct-fed microbials and yeast on site and extent of digestion, blood chemistry, and subclinical ruminal acidosis in feedlot cattle. J Anim Sci 81: 1628-1640.

8. Nocek JE, Kautz WP, Leedle JAZ, Block E (2003) Direct-fed microbial supplementation on the performance of dairy cattle during the transition period. J Dairy Sci 86: 331-335.

9. Nocek JE, Kautz WP, Leedle JAZ, Allman JG (2002) Ruminal supplementation of direct-fed microbials on diurnal $\mathrm{pH}$ variation and in situ digestion in dairy cattle. J Dairy Sci 85: 429-433.

10. Lila ZA, Mohammed N, Yasui T, Kurokawa Y, Kanda S, et al. (2004) Effects of a twin strain of Saccharomyces cerevisiae live cells on mixed ruminal microorganism fermentation in vitro. J Anim Sci 82: 1847-1854.

11. Harrison GA, Hemken RW, Dawson KA, Harmon RJ, Barker KB (1988) Influence of addition of yeast culture supplement to diets of lactating cows on ruminal fermentation and microbial populations. J Dairy Sci 71: 2967-2975.

12. Mutsvangwa T, Edwards I, Topps JH, Paterson GFM (1992) The effect of dietary inclusion of yeast culture (Yea-Sacc) on patterns of rumen fermentation, food intake and growth of intensively fed bulls. Anim Sci 55: $35-40$.

13. Kenney NM, Vanzant ES, Harmon DL, McLeod KR (2015) Effect of direct-fed microbials on utilization of degradable intake protein in receiving steers. Can J Anim Sci 95: 93-102.

14. Kenney NM, Vanzant ES, Harmon DL, McLeod KR (2015) Directfed microbials containing lactate-producing bacteria influence ruminal fermentation but not lactate utilization in steers fed a highconcentrate diet. J Anim Sci 93: 2336-2348.

15. Goering HK, Van Soest PJ (1970) Forage Fiber Analyses. In: Agriculture Handbook No 379. Agricultural Research Service, United States Department of Agriculture. 
16. Erwin ES, Marco GJ, Emery EM (1961) Volatile Fatty Acid Analyses of Blood and Rumen Fluid by Gas Chromatography. J Dairy Sci 44: 1768-1771.

17. Ottenstein DM, Bartley DA (1971) Improved gas chromatography separation of free acids C2-C5 in dilute solution. Anal Chem 43: 952-955.

18. Kun E, Kearny EB (1974) Methods of Enzymatic Analysis. $2^{\text {nd }}$ English Edition.

19. Kristensen NB (2000) Quantification of Whole Blood Short-chain Fatty Acids by Gas Chromatographic Determination of Plasma 2-chloroethyl Derivatives and Correction for Dilution Space in Erythrocytes. Acta Agric Scand A Anim Sci 50: 231-236.

20. Husek P, Liebich HM (1994) Organic acid profiling by direct treatment of deproteinized plasma with ethyl chloroformate. J Chromatogr B Biomed Appl 656: 37-43.

21. Pitt RE, Cross TL, Pell AN, Schofield P, Doane PH (1999) Use of in vitro gas production models in ruminal kinetics. Math Biosci 159: 145-163.
22. Theodorou MK, Williams BA, Dhanoa MS, McAllan AB, France J (1994) A simple gas production method using a pressure transducer to determine the fermentation kinetics of ruminant feeds. Anim Feed Sci Tech 48: 185-197.

23. Jeyanathan J, Martin C, Morgavi DP (2016) Screening of bacterial direct-fed microbials for their antimethanogenic potential in vitro and assessment of their effect on ruminal fermentation and microbial profiles in sheep. J Anim Sci 94: 739-750.

24. Kristensen NB (2001) Rumen microbial sequestration of [2-(13)C] acetate in cattle. J Anim Sci 79: 2491-2498.

25. Baldwin RL, Wood WA, Emery RS (1962) Conversion of Lactate- $\mathrm{C}^{14}$ to Propionate by the Rumen Microflora. J Bacteriol 83: 907-913.

26. Nocek JE, Kautz WP (2006) Direct-fed microbial supplementation on ruminal digestion, health, and performance of pre- and postpartum dairy cattle. J Dairy Sci 89: 260-266. 